\title{
Desnudando el falangismo: las dificultades para la implantación de FET de las JONS en Galicia (1936-1945)
}

\author{
Undressing Falangism: the difficulties for the \\ implantation of FET de las JONS in Galicia (1936-1945) \\ ADRIÁN PRESAS SOBRADO \\ Universidad de Vigo \\ http://orcid.org/0000-0003-2809-2528 \\ apsobrado@gmail.com
}

\section{RESUMEN}

El partido único de la dictadura franquista se enfrentó a dos problemas clave en su proceso de construcción: la carencia de una masa social fuerte que lo sustentase y su incapacidad para obtener y movilizar recursos económicos. La unificación de falangistas y tradicionalistas aumentó las dificultades del partido, dividiéndolo en dos almas que vieron como entraba en sus filas un enorme caudal de hombres de tradiciones políticas diferentes a las suyas. La unificación de los cargos de gobernador civil y jefe provincial del Movimiento no hizo más que confirmar el papel subordinado de FET de las JONS dentro del edificio institucional y político de la dictadura.

Palabras clave: Franquismo, FET de las JONS, gobernador civil, elites políticas, institucionalización

\section{Abstract}

The single party of Franco's dictatorship faced two key problems in its construction process: the absence of a strong social support and its incapacity in obtaining and mobilizing economic resources. The merge in one single body of falangists and traditionalists increased the party's problems dividing it in two souls which saw how a enormous flow of men from different political traditions entered in its organization. The unification of the Administrative Provincial Chief - Civil Governor- and the Provincial Movement's Chief positions confirms the subordinated role of FET de las JONS inside the dictatorship's institutional and political structure.

Keywords: Francoism, FET de las JONS, Civil Governors, political elites, institutionalization

\section{INTRODUCCIÓN}

Es un lugar común en la historiografía sobre la construcción de la dictadura franquista en el ámbito local abordar dos temas que, por su abundancia, devienen inexcusables en todos los textos. El primero de los temas es el debate recurrente sobre la naturaleza 
política de la dictadura franquista. Cientos de páginas ha ocupado y ocupa la preocupación de los historiadores españoles de dar respuesta a la pregunta sobre la definición política de la dictadura: fascista, autoritaria, militar, teocrática, totalitaria... Una pregunta que, a juicio de dos historiadores fundamentales en toda la producción científica sobre la dictadura franquista, estaba ya en los años 90 del siglo XX agotada por completo (Aróstegui, I992; Tusell, I993).

El segundo de los temas es la fortaleza o debilidad; el artificio o sostenibilidad; el fascismo o la fascistización de un proyecto político que las autoridades dictatoriales querían colocar como bulbo de proa del régimen: el pretendido partido único, el Movimiento Nacional, FET de las JONS. Según los estudios, la dictadura se habría dotado de una herramienta para la movilización de la masa social. Esa movilización se habría producido en los cuatro sentidos de la actividad humana: política, economía, sociedad y cultura. Todo ello bajo el calificativo de «relaciones sociales». La historiografía, por lo tanto, dota al partido único de unas características que, irremediablemente, se manifiestan parejas a las de la naturaleza política de la dictadura. Es decir: estamos ante un partido fascista; estamos ante un partido fascistizado; estamos ante un movimiento vacío de cualquier maniobra de acción; estamos ante un partido artificial, etc. Todos los textos coinciden — aquí sí, sin ningún tipo de disonancia-, en que el partido único carecía de los recursos, por lo tanto, de capacidad para desarrollar las misiones que las autoridades le encomendaron.

En este trabajo se analizará la construcción del partido único de la dictadura en las cuatro provincias gallegas. Se pretende determinar como construyeron el edificio del partido las élites políticas locales; como se adaptaron a las circunstancias políticas y sociales cambiantes de los primeros años de la dictadura y como intentaron extender su influencia entre la sociedad. Se busca, también, localizar las principales trabas con que se encontró el partido único para desarrollar su actividad. Se intentarán identificar las relaciones entre las diferentes facciones que integraban FET de las JONS - falangistas y tradicionalistas, fundamentalmente; pero también católicos-, y la difícil asimilación —a los ojos de los falangistas de camisa vieja-, de aquellos que habían entrado en la organización una vez iniciada la guerra civil.

Para realizar esta investigación se han trabajado dos fondos del Archivo General de la Administración, de Alcalá de Henares, Madrid (Ministerio de Cultura y Deporte): Secretaría General del Movimiento y el fondo de la Delegación Nacional de Provincias. Se han tratado los expedientes de las cuatro provincias gallegas resultando un total de cincuenta y cuatro unidades documentales de diferente extensión.

La naturaleza de los documentos estudiados es variada. Lo más abundante son los informes emitidos por los diversos órganos provinciales de FET de las JONS a las delegaciones nacionales de servicios correspondientes. En ellos, los jefes provinciales del Movimiento y los jefes de servicios del partido comunican a los órganos centrales las necesidades y problemas que afectaron a la organización. Dentro de la misma naturaleza documental existen otros documentos que describen con mayor prolijidad el estado del Movimiento en las provincias gallegas. La otra tipología más abundante son los denomi- 
nados «partes mensuales» de información. En ellos, las jefaturas provinciales informaban del funcionamiento de los distintos servicios del partido de mes en mes.

La documentación utilizada para este trabajo es, por lo tanto, fruto de la producción administrativa del propio partido. En ella no sólo se reflejan las situaciones que debió afrontar el Movimiento de las cuatro provincias gallegas; también las sensaciones, perspectivas, lecturas e interpretaciones que los cargos provinciales hacían de la realidad de su territorio. De ahí su importancia para el estudio del poder local y provincial y las tensiones que se producían dentro de FET de las JONS.

No se pretende lograr una definición ideológica del partido; ni ampliarla, en la manera de forma política adoptada por el Estado, al ámbito del conjunto de la dictadura. Se intentan localizar y describir los elementos de funcionamiento anteriormente citados para obtener una imagen lo más fiel posible del partido; imagen que puede ayudar a acercarnos con más detalle a una definición política exacta de la dictadura.

\section{UNA FALANGE GALLEGA DESPOBLADA}

El gobernador civil de Pontevedra, Mateo Torres Bestard, en su labor de información al gobierno sublevado, emitió un «juicio sucinto» sobre el estado político de la provincia bajo su mando en 1937. Nada funcionaba correctamente. Aunque en el proceso de renovación de comisiones gestoras había conseguido colocar a miembros de FET de las JONS, estas no funcionaban convenientemente debido a lo que él denominó actividad de «mangoneo». Los «mangantes» eran los que Torres Bestard etiquetaba como «caciques» que, desde su punto de vista, gozaban de gran raigambre en la provincia pontevedresa. De esa manera — continuaba su explicación el gobernador civil—, era imposible que FET de las JONS contase con la ayuda de la masa social; y según su interpretación, el Movimiento no era «simpático» entre los pontevedreses. Torres Bestard entendía que el mejor remedio para corregir los problemas de la Falange pontevedresa era organizarla de manera efectiva, colocando en los cargos más importantes a aquellos que demostrasen las mejores aptitudes; para así conseguir un «partido limpio de demagogias de todo color y cuya actuación en la práctica estuviera a tono con los postulados que preconiza». El gobernador Mateo Torres era consciente de que en su provincia el control político estaba en manos de los prohombres de los partidos de derechas anteriores a la guerra civil; y que estos continuaban su lucha política «principalmente contra Falange Española», afiliando en la organización de la dictadura a sus correligionarios para, de acuerdo al punto de vista del gobernador, «dar, con la fuerza, [con] el Poder [sic]». La sensación de Torres Bestard era que el poder de los «caciques» locales era tal, que el decreto de unificación en la Falange pontevedresa:

«[...] que aquí se hizo sobre el papel nada más; a fines de 1937 se llevó a cabo prácticamente la de los hombres; y en el año en curso se ha efectuado, relativamente, la 
del elemento femenino; pero, sobre todo este último sigue la sorda lucha entre una procedencia y otra» ${ }^{1}$.

Según los informes emitidos, la situación del partido era crítica en Galicia; en todas las provincias. La falta de personal afiliado y la incursión de los personajes clásicos de la política provincial habrían configurado un Movimiento inane, inerte desde el principio de la dictadura como máquina administrativa y de encuadramiento social. En 1937-1938, la delegación central de FET de las JONS envió a Coruña a un teniente coronel que realizaría una inspección provincial al partido. Su conclusión de la visita realizada fue cristalina: «mi impresión, no pudo ser más deleznable, no existe nada [subrayado en rojo] y lo poco que existe es para desprestigiar nuestro Movimiento, tanto por la calidad como por el número». Nada funcionaba en las provinciales gallegas, y lo poco que lo hacía sería para manchar el nombre de FET de las JONS. El principal problema se encontraba en las jefaturas locales del Movimiento — las más próximas a los gallegos—, que, según los informes de las jefaturas provinciales, no colaboraban económicamente con la organización. En Ourense, y en la misma línea, tampoco «existe nada» en relación con el partido único. Algunos servicios del Movimiento, como la Organización Juvenil, estaba «cargada de deudas», a pesar de los donativos que recibía de manera continua de parte de sus benefactores. Es más, el inspector de la provincia coruñesa identifica el problema del partido en que este estaba en manos de «chiquillos» que no sabían manejar una organización de aquel estilo ${ }^{2}$. El Movimiento caminaba sin rumbo y sin ritmo. Las provinciales solicitaban a Madrid que determinase «prontamente le trayectoria a seguir». Cuando se referían a trayectoria, las jerarquías coruñesas querían saber cuál sería el «rumbo fijo» del proyecto dictatorial:

«[...] si la nueva España, ha de ser francamente azul, un solo color ha de intervenir en su composición: si se pretende un color, blanco, ya sabemos por la física que éste [sic] color se determinará por la aglutinación de varios colores» ${ }^{3}$.

Lo que evidencian las jerarquías gallegas es una tendencia similar a la dinámica que se producía en el resto de España. El partido unificado era una cáscara vacía de militantes de primera hora; había pocas camisas viejas. Fue por esto por lo que para encontrar hombres que cubriesen los cargos públicos en la naciente burocracia dictatorial, hubo que ha-

1 Todas las citas anteriores en Archivo General de la Administración (AGA), Movimiento Nacional (MN), Delegación Nacional de Provincias (DNP), 1938, Estado de la diputación provincial y de la provincia de Pontevedra, sig. 44/3122.

2 Para el caso de A Coruña: AGA, MN, Delegación Nacional de Provincias (DNP), 2 de noviembre de 1939, Informe sobre Coruña y Lugo, sig. 51/20529. El ejemplo de Ourense: AGA, MN, DNP, 17 de octubre de 1939, Expediente instruido al Delegado de OJ, sig. 51/20520.

3 AGA, MN, DNP, 2 de noviembre de 1939, Informe sobre Coruña y Lugo, sig. 51/20529. En el caso de Ourense, la desorganización y el vaciado de todo contenido administrativo llegaba al extremo de decir que el partido y sus servicios existían «tan sólo nominalmente», AGA, MN, DNP, julio de 1940, Parte quincenal de la provincia de Ourense del 1 al 15 de julio, sig. 51/20520. 
cer hueco a todos aquellos que quisiesen colaborar de una u otra manera en la edificación del armazón administrativo e institucional de la dictadura. De ahí, que debamos hablar de un partido donde lo que primaba era la unión de personas a través de sus intereses particulares coincidentes (González Madrid, 2004: 34-35). Por eso, aunque se puede hablar de la fuerza de la FE de las JONS anterior a la guerra civil, esa fuerza se circunscribía a su discurso y capacidad de encender las pasiones políticas de aquellos que se decidían a entrar en ella o se mantenían a su alrededor. A pesar de eso, la Falange era un partido débil. La existencia de una guerra civil en su configuración como partido único de un régimen dictatorial condicionó de manera definitiva aquel proceso. De manera diferente a lo que sucedió en Alemania e Italia, la Falange había convivido en su biotopo con un variado conjunto de partidos políticos de su mismo espectro ideológico — la derecha, más o menos reaccionaria-, que constituían una biota rica pero de difícil trayectoria común. FE de las JONS cargó siempre con la dificultad de carecer de una masa social amplia y compacta a su lado (Canales Serrano, 2006: 235-236; Ginés i Sànchez, 2010: 84-85).

Para las falanges gallegas se hacía necesario tener indicaciones exactas sobre el rumbo a tomar, porque dentro de ellas las jerarquías identificaban distintas facciones o grupos que intentaban situar sus intereses individuales al frente de la acción política y social. Son varios los ejemplos de divisiones internas que se pueden ofrecer. Por ejemplo en A Coruña, donde se hablaba de «falangistas de primera y de tercera». Los falangistas de primera eran los seguidores del jefe provincial del Movimiento coruñés, Gerardo Salvador Merino, definidos como un grupo «perturbador que impunes hasta el momento realizan cuanto les viene en gana». Sucedía algo similar en Ourense, donde Casiano Costas Posada — primer gobernador civil que ejerció de jefe provincial—, indicaba la existencia de varios grupos ( «banderías y capillitas») que no se sometían a sus directrices y que actuaban por libre con la única misión de «obtener puestos para su medro personal o satisfacer su voluntad». Costas Posada hizo una descripción detallada de quienes eran los que dividían su Falange desde el interior. Identificó unos falangistas de pura cepa que controlaban el partido empleando todos los medios a su alcance; y al otro grupo de «Hedillistas [subrayado]», que practicaban una «resistencia pasiva». Las divisiones, según Costas Posada, afectaban a todos los servicios del partido fomentando «rencillas y rivalidades personales» que él entendía eran «lamentable herencia del derrocado régimen, con gran regocijo de los enemigos de la organización» ${ }^{4}$.

Así, fruto de las variadas procedencias de los falangistas, una vez iniciada la guerra civil, en cada región española se desarrollaron unos cuadros políticos y administrativos de distintas procedencias. En el País Valenciano el músculo de los católicos de la Derecha

4 Las citas de A Coruña se corresponden con AGA, MN, DNP, 29 de septiembre de 1939, Anónimo pidiendo una investigación para normalizar la Falange local cuya situación dice ser pésima, sig. 51/20529. Las palabras de Casiano Costas en AGA, MN, DNP, julio de 1940, Parte quincenal del 1 al 15 de julio, y también en: agosto de 1940, Parte quincenal del 1 al 15 de agosto, y marzo de 1941, Parte mensual del mes de febrero, sig. 51/20520. 
Regional Valenciana se transfirió casi por completo al partido unificado (Calzado Adaria y Torres Fabra, 1993: 29-40; Gómez Roda, 1998: 81-85). Lo mismo sucedió en La Rioja, donde los conservadores republicanos de la CEDA local se pasaron en masa al inicio del partido único (Rivero Noval, 2001: 181 y 192); o en Las Palmas de Gran Canaria, donde los católicos de la Acción Popular local había ejercido la doble militancia en el falangismo y en el catolicismo palmense (Millares Cantero, 2014). En Cataluña, los estudios describen cómo algunos elementos de la Lliga pudieron acabar dentro de FET de las JONS, siguiendo la estela de las distintas marcas de las CEDA locales (Marín i Corbera, 2000: 224-226) . Poderoso caballero era don Dinero. Movimientos como los de los militantes de la Lliga catalana se explican por los aportes económicos que estos hicieron para financiar el desarrollo de la guerra civil. Aunque estos elementos se encuadrarán primero en la Comunión Tradicionalista - por la obvia cercanía en la militancia dentro del sector reaccionario más conservador de la Iglesia católica española; y por el marcado carácter regionalista del partido catalán—; tuvieron que pasar, irremediablemente por el aro de la unificación (Thomàs, 1992: 68-126).

\section{LOS PROBLEMAS DE ORGANIZACIÓN DE FALANGE}

La unificación decretada de falangistas y tradicionalistas en abril de 1937 no hizo más que enfatizar las taras del nuevo partido y las diferencias de cultura política en su interior. La dinámica del aluvión — que se describe desde el mes de septiembre de 1936 (Giráldez Lomba, 1999: 120) —, va a determinar una FET de las JONS incapaz. Los cuadros de mando - jefes locales, jefes provinciales, secretarios, delegados locales y provinciales de servicios, secretarios de servicios, secretario general del Movimiento, etc.eran incapaces de actuar como motor de la organización, porque la correa de transmisión — los militantes_-, se mostraban apáticos, desconectados, ajenos a todo lo que tuviese que ver con el partido. Los militantes perdían el interés en el partido cuando conseguían sus objetivos vitales (Mas Quetglas, 2003: 98). La participación en el Movimiento daba acceso al mercado laboral de manera más rápida y efectiva. Pertenecer a FET de las JONS era la mejor tarjeta de presentación. De ahí, al vaciado de hombres que formaban la estructura del partido, no hubo que recorrer mucho camino.

Esas divisiones internas tan acusadas acabaron provocando en la organización de FET de las JONS gallega auténticas dificultades para llegar a la ciudadanía. El gobernador civil y jefe provincial de Pontevedra, Francisco Rodríguez Acosta, explicaba a las jerarquías de Madrid que la Falange pontevedresa era una construcción ficticia. En un informe

5 Se descubren estos movimientos, también, en el municipio de Girona, estudiado por Clara (1991): 45.

6 Este estudio de historia local, entre otros aspectos interesantes del ámbito urbano, define claramente ese proceso de engorde de las listas de afiliados. El autor entrevistó a un falangista de la ciudad de Vigo que expresó en estos términos el proceso: «Luego vino el aluvión, todo el mundo era de Falange y la Falange se hincó como un globo». 
afirmaba que «virtualmente podía decirse que no había organización en la provincia». En otra circular, Rodríguez Acosta decía a los jefes locales que hiciesen frente a las críticas de aquellos que atacaban al Movimiento. La crítica, decía el gobernador civil, es «hija de una alegre ignorancia y siempre favorecerá al designio y manejos de nuestros enemigos». El partido carecía de militantes activos y que se implicasen en su día a día. Se llegaba a admitir que los afiliados vivían absolutamente ajenos al funcionamiento y actividad del Movimiento buscando únicamente el carné de militante porque «evita el salvoconducto» ${ }^{7}$. Con el paso del tiempo, esa desconexión de la sociedad respecto al partido se hizo más evidente. El jefe provincial coruñés, Diego Salas Pombo, comentaba en 1943, en plena segunda guerra mundial, que la población se mostraba apática respecto de la parafernalia del partido. La masa no se manifestaba jubilosa ni en los aniversarios por la muerte de José Antonio. En Pontevedra, la situación social respecto al partido era similar, con una «gran masa de opinión indiferente, neutra, o los llamados de orden» ${ }^{8}$.

El partido se veía en la obligación de configurar estrategias que le permitiesen hacerse notar entre la sociedad provincial. Una de las maneras propuestas fue la presentada por el jefe provincial de Lugo y futuro gobernador civil, Ramón Ferreiro. Aún con una Falange provincial diezmada de recursos humanos, Ferreiro proponía a Madrid que los «organismos de carácter político y administrativo estén encarnados en personas de las que el Partido pueda responder sobre su modo de sentir y actuación». Es decir: FET de las JONS pretendía hacerse con el control de municipios, diputaciones y todo el entramado administrativo que se estaba configurando en los primeros compases de la posguerra. Todo ello a pesar de no tener un apoyo militante con la suficiente fuerza. Las jerarquías provinciales eran conscientes de la escasa implicación de los que figuraban como militantes. Por esa razón, el partido debió acometer una depuración intensa —en unos territorios con más intensidad que en otros_-, para determinar los límites entre la militancia activa y los que, como se dijo anteriormente, militaban de cara a la galería. De ahí que las inspecciones a las jefaturas locales resultasen esenciales para que «rindan la eficacia que con ellas se persigue» ${ }^{9}$. Ahora bien, las jefaturas provinciales eran incapaces de realizar inspecciones de manera activa, dinámica, porque el Movimiento gallego carecía de recursos

7 AGA, MN, DNP, enero de 1941, Parte mensual de la provincia de Pontevedra del mes de diciembre, sig. 51/20560. AGA, MN, DNP, noviembre de 1940, Parte mensual de la provincia de A Coruña del mes de octubre, sig. 51/20529.

8 AGA, MN, DNP, diciembre de 1942, Parte mensual de la provincia de A Coruña del mes de noviembre; y junio de 1943, Parte mensual de la provincia de Pontevedra del mes de maio, sig. 51/20621.

9 AGA, MN, DNP, octubre de 1940, Parte mensual de la provincia de Lugo del mes de septiembre; y enero de 1941, Parte mensual de la provincia de Lugo del mes de diciembre, sig. 51/20533. Sobre la celeridad en la depuración de militantes, en el caso de Ourense, el jefe provincial, Casiano Costas Posada, fue advertido por la Delegación Nacional de Provincias de que era necesario hacer algo nuevo cada mes. En mayo de 1941, después de varios meses diciendo a Madrid que se hacían pocas cosas en la depuración del partido, el revisor en Madrid escribió en la hoja del parte mensual: «No se puede admitir esto, porque en la labor de depuración debe hacerse algo nuevo todos los meses». AGA, MN, DNP, junio de 1941, Parte mensual de la provincia de Ourense del mes de mayo, sig. 51/20520. 
para poder hacerlo. El jefe coruñés, Lorenzo Vilallonga Lacave, se lamentaba en julio de 1940 de que no podía realizar las inspecciones que quería. En un informe se lamentaba de que los vehículos debían «permanecer en el garaje» por no tener gasolina con la que llenar los depósitos. En la provincial de Pontevedra, Francisco Rodríguez Acosta se excusaba de no hacer más inspecciones porque el «autoplano» que debían utilizar era de «bastante más consumo que los Balillas», que estaban inmovilizados «por falta de cubiertas». El gobernador civil y jefe provincial de Ourense, Antonio Martín Ballesteros, no podía hacer inspecciones por falta de combustible ${ }^{10}$.

Cuando todos los inconvenientes se solucionaban y se podían hacer las inspecciones, lo que se encontraban los inspectores provinciales en las locales era un panorama desolador. A finales de 1940, la inspección provincial coruñesa tenía como único objetivo acabar con las «discrepancias existentes» en los diferentes puntos de la provincia. Los militantes de FET de las JONS expresaban con mayor intensidad sus diferencias en el ámbito de los ayuntamientos y pequeñas corporaciones vecinales. En septiembre de 1941, el jefe provincial coruñés Diego Salas Pombo, comunicaba que en locales como Pontedeume la situación era «deplorable». Eso era la tónica de toda la provincia. El panorama provincial dibujado por el jefe provincial coruñés era el de unas locales sumidas en el completo decaimiento de sus militantes, hasta el punto de que la situación era de «franca descomposición todo [sic]» y la acción «de esta provincia es realmente caótica» ${ }^{11}$. La generalidad de las Falanges gallegas era esa: una situación «bastante mala en general». Los presupuestos y los ingresos no llegaban para cubrir las necesidades de la actividad del partido. Las jefaturas locales desarrollaban una actividad «precaria» debido a la falta de fondos «viéndose en algunos casos obligadas a dejar los locales que ocupan por no poder costear su alquiler». Había dos casos ejemplares en la provincia pontevedresa de ese extremo: las jefaturas de Sanxenxo y Vilaboa tenían su sede en la casa particular de los jefes locales ${ }^{12}$.

Mientras se producía la construcción del régimen institucional de la dictadura, FET de las JONS no sólo tuvo que enfrentarse a la debilidad de sus cuadros; sino que también hubo de encarar las tensiones interadministrativas. Los gobernadores civiles fueron la pieza clave en la organización institucional de la dictadura. Ya desde los primeros compases de la guerra civil, el cargo de gobernador civil se subordinaba totalmente al mando central quedando la ejecución de todas las disposiciones en sus manos. El control del

10 AGA, MN, DNP, julio de 1940, Parte quincenal de la provincia de A Coruña del 1 al 15 de julio de 1940, sig. 51/20529. AGA, MN, DNP, enero de 1943, Parte mensual de la provincia de Pontevedra del mes de diciembre, sig. 51/20595. AGA, MN, DNP, abril de 1944, Parte mensual de la provincia de Ourense del mes de marzo, sig. 51/20648.

11 AGA, MN, DNP, enero de 1941, Parte mensual de la provincia de A Coruña del mes de diciembre, sig. 51/20529. AGA, MN, DNP, mayo de 1942, Parte mensual de la provincia de A Coruña del mes de abril, sig. 51/20586.

12 AGA, MN, DNP, mayo de 1943, Parte mensual de la provincia de Pontevedra del mes de abril, sig. 51/20621. 
orden público o el nombramiento de alcaldes y concejales eran decisión de aquéllos; que con el discurrir de la guerra y bajo la excusa de la adquisición de «la experiencia de casi un año», pasaban a depender del ministerio de la Gobernación: una «vuelta al principio unitario» en la gestión territorial ${ }^{13}$. Dado el poder de los gobernadores civiles, no es de extrañar que FET de las JONS viese en ellos a uno de sus muchos enemigos. El control del gobernador civil sobre la provincia era casi omnímodo, pues solo respondía ante los responsables del gobierno central. Además, las autoridades impusieron una duración breve —estimada para el período entre 1938 y 1958 en tres años y medio—, en el cargo para evitar que se creasen redes políticas que pusiesen en riesgo la centralidad del poder (Ponce Alberca, 2016).

\section{LA UNIFICACIÓN DE LOS CARGOS PROVINCIALES}

En Lugo, el jefe provincial del Movimiento, Ramón Ferreiro, enviaba a Madrid sus informes que expresaban efusivamente las excelencias del Movimiento lucense. En julio de 1940, el jefe provincial decía que la Falange lucense no tenía «figura de talla con la que tenga que enfrentarse», y se lanzaba a pedirle a la jerarquía del Estado «que nos utilice más intensamente». Aun así, Ferreiro identificaba la posibilidad de que dentro del partido existiesen elementos que no siguiesen la línea marcada por él. Así que según su parecer, para que el Movimiento fuese efectivo describió que los «organismos de carácter político y administrativo estén encarnados en personas de las que el Partido pueda responder sobre su modo de sentir y su actuación». Con el paso de los meses, en 1944, el nuevo gobernador civil y jefe provincial, Santiago Vallejo Heredia, aportó el gusto a la retórica del Movimiento y completaba la información de sus partes con construcciones repetitivas que pretendían transmitir el ambiente ideal de la provincia lucense:

«En este aspecto cada vez se va dando mayor impulso al referido ambiente a fuerza de poner en práctica todos cuantos medios faciliten una labor de justicia social que, como tal, ejerce su influjo y acusa cada vez mejores resultados».

Bajo su mando, en abril de 1946, la situación de su provincial era tan extraordinaria — por su capacidad de desplegar todo el contenido programático—, que según du descripción, el partido vivía en «progresión ascendente hacia lo favorable» ${ }^{14}$.

13 Instrucciones del 5 de octubre de 1936, BOE, 6 de octubre de 1936, 2: 7-8. La institucionalización del ministerio de la Gobernación en la Ley de 29 de diciembre de 1938, BOE, 31 de diciembre de 1938. 183 : 3217.

14 AGA, MN, DNP, julio de 1940, Parte quincenal de la provincia de Lugo del 1 al 15 de julio; y enero de 1941, Parte mensual de la provincia de Lugo del mes de diciembre, sig. 51/20533. AGA, MN, DNP, febrero de 1944, Parte mensual de la provincia de Lugo del mes de enero, sig. 51/20645. AGA, MN, DNP, mayo de 1946, Parte mensual de la provincia de Lugo del mes de abril, sig. 51/20674. 
A la luz de lo dicho por las jerarquías lucenses, al Movimiento la unificación de los cargos de gobernador civil y jefe provincial le habría sentado como anillo al dedo. Antes de mayo de 1941 — fecha en la que el jefe provincial Ramón Ferreiro se hace también con el puesto de gobernador civil—, las relaciones entre las dos jerarquías provinciales eran tirantes por ser estas inexistentes. Según lo relatado por Ferreiro, Pedro Morales Pleguezuelo —el gobernador civil que le antecedió-, mantenía una relación nula con FET de las JONS por la «frialdad que para todas las cosas del Partido» manifestaba ${ }^{15}$. La mala relación entre los gobernadores civiles y los jefes provinciales del Movimiento era una constante descrita en los informes del período estudiado. La delegada provincial de la Sección Femenina de Ourense se dirigió a la Delegación Nacional de Provincias para informarla de que el gobernador civil, Casiano Costas Posada, les hacía «la vida imposible», al negarles a las distintas delegaciones el uso de los vehículos que, en principio, estaban a su disposición ${ }^{16}$. La variedad en la selección de los nombres para los cargos unificados se solucionó en Galicia de dos maneras: gobernadores civiles que suman el cargo de jefes provinciales - A Coruña, Jesús María Iraola Palomeque; en Ourense, Casiano Costas Posada y en Pontevedra, Francisco Rodríguez Acosta-; y jefes provinciales que acabaron siendo gobernadores — Ramón Ferreiro en Lugo ${ }^{17}$. En aquellas provincias donde la presencia de FET de las JONS era más débil —o carecía de suficientes miembros-, el gobernador civil se hizo cargo del partido; mientras que donde hubo un partido fuerte el jefe provincial accedió al principal cargo administrativo provincial. Una vez producida la unificación, los gobernadores civiles se lanzaron a redactar y publicar circulares con el pretexto de la «necesidad de coordinar los Organismos públicos con los Servicios del Partido»; especialmente aquellos del ámbito municipal ${ }^{18}$. El éxito de las medidas, como vemos, no fue el esperado.

La unificación de los cargos políticos de gobernador civil y jefe provincial del Movimiento convirtió al primero de ellos en el elemento esencial, en la «pieza más importante», en la organización administrativa española por su doble condición política y administrativa. La ciencia política de la academia franquista delimitó perfectamente el papel de FET de las JONS en el entramado institucional de la dictadura. Según aquélla, la unión de los cargos —en la vertiente política y administrativa-, no fue más que la manifestación de que la dictadura, «sin un juego de partidos políticos», no tuvo la necesidad de «aislar a la administración de éstos [partidos]». La separación de las dos figuras provinciales habría provocado que el sistema se contrarrestase de manera negativa. Esta manera delicada

15 AGA, MN, DNP, 1941, Informe del Jefe Provincial, sig. 51/20555.

16 AGA, MN, DNP, 13 de mayo de 1940, Problema político entre el gobernador y el Jefe provincial, sig. $51 / 20520$.

17 Casiano Costas y Francisco Rodríguez unifican en su persona las dos jerarquías en mayo y noviembre de 1940, respectivamente; Jesús María Iraola accede a la jefatura del Movimiento después de ser nombrado gobernador civil en la tardía fecha de marzo de 1945. Ramón Ferreiro se convierte en gobernador civil en mayo de 1941, habiendo sido nombrado jefe provincial del Movimiento en septiembre de 1938. 
de reconocer que existían problemas de acción entre los gobernadores civiles y los jefes provinciales se solucionó con la unificación. Así se habría conseguido que la influencia política — la de FET de las JONS—, «se hace notar» en la vertiente administrativa — la de los gobernadores civiles-; de tal manera que la evolución de la administración se impregnó de los principios políticos. Pero la vertiente administrativa era siempre la más importante. Los gobernadores civiles se convirtieron en «hombres del Movimiento»:

\begin{abstract}
«Hombres que han ido formando sus ideas políticas con posterioridad al 18 de julio de 1936, y cuyo bagaje ideológico anterior no presentaba, bien por razón de edad o por otras circunstancias, especiales y definidas características, sino que pertenecen a la mentalidad normal de quienes deseaban una España fuerte, pacificada, en orden y en el camino de su prosperidad» (Herrero Tejedor, 1962: 12-21 y 43).
\end{abstract}

A pesar de todo lo anterior, FET de las JONS desarrolló un papel esencial dentro de la dictadura franquista. Como se refirió más arriba, los hombres que tenían intención de medrar en el entramado institucional y político de la dictadura se encuadraron en el partido. El carné del Movimiento podía abrir puertas para cargos municipales, provinciales o administrativos que reportaban beneficios económicos para los individuos. Para el acceso a estos puestos era preceptivo contar con informes favorables de tres instancias: la Guardia Civil, la Iglesia — aunque no siempre-, y FET de las JONS. Para que el gobernador civil pudiese remitir los nombres de los candidatos a los cargos al ministerio correspondiente, y que éste realizase el nombramiento, debía contar con informaciones que sustentasen la valía y capacitación de aquéllos. Por lo tanto, la militancia en el Movimiento, más unos antecedentes adecuados — militantes en «partidos de orden»; «siempre de orden»; «adicto al Movimiento»; «siempre adicto al Movimiento»; «moral falangista»; y el siempre puro «apolítico»—, eran fundamentales para que las informaciones de FET de las JONS fuesen favorables a los candidatos.

\title{
LA DEBILIDAD DE LA FALANGE GALLEGA EN PERSPECTIVA COMPARADA
}

La escasez de cuadros políticos y administrativos de FET de las JONS se vio acentuada por la bicefalia en la gestión provincial. En aquellas provincias en las que se estudia el poder local y provincial se describen numerosos sucesos que expresan claramente el papel subordinado de FET de las JONS a la hora de participar en el ejercicio del poder político y administrativo. El partido pretendía que la vertiente política se impusiese sobre la administrativa - los gobernadores y alcaldes-; en una lucha que había sucedido también en Italia entre el federale — el jefe del partido fascista - y el prefetto —el jefe de la administración- (Cenarro Lagunas, 1997: 112). La unificación de los cargos de gobernador civil y jefe provincial del Movimiento, a partir de 1939, puso fin a las disputas. Falange esperaba que el dominio total del panorama político que buscaba llegase con la tan ansiada unión. La experiencia histórica demuestra que no fue así. Las luchas internas 
entre las facciones y el acorralamiento por parte de las autoridades administrativas de la dictadura la dejaron en la posición subalterna que había desarrollado hasta aquellos momentos (Ginés i Sànchez, 2010). En el instante en que los gobernadores civiles se hicieron cargo del partido acometieron reorganizaciones administrativas que sacaron a la luz numerosos conflictos de intereses (Presas Sobrado, 2019: 175-177).

Falange habría perdido su sentido primigenio de ser un factor movilizador; pero ganó otro: gran colocadora de sus cuadros en los cargos políticos y administrativos de la dictadura. FET de las JONS se convirtió en el trampolín de aquellos que deseaban un lugar en la vida pública dictatorial. La pertenencia a Falange abría la puerta a informes favorables, a favores personales, a cargos municipales y provinciales, a puestos en la Administración, etc. Mas, en algunas zonas de la geografía española esa idea de partido escoba ha sido puesta en cuestión; especialmente en los núcleos rurales. La primigenia FE de las JONS habría tenido un enorme éxito entre los campesinos al haber sido el núcleo de su discurso fascista. El obrero del campo se habría colocado, en virtud de ese discurso, en la posición de ser uno más dentro de la cadena de producción a la que interpelaban los primigenios falangistas (Lazo Díaz, 1998: 32-33).

La historiografía española sobre la construcción del partido único de la dictadura franquista ha arrojado resultados similares a los referidos más arriba. El escaso poder de FET de las JONS, tanto antes como después de la unificación, se manifestó claramente en otras zonas del territorio español. La evidencia de este extremo se manifestó, por ejemplo, en las provincias de València i Castelló (Ginés i Sànchez, 2010). De igual manera que sucedió en las cuatro provincias gallegas, la carencia de personal — afiliados—, dentro del Movimiento se asocia a su incapacidad para acercarse a las clases populares. El estudio de las provincias del Levante concluye que al partido le costó llegar, incluso, a las clases dominantes; es decir, a aquellos que tenían poder económico para apoyar su construcción. Esa situación de auténtico vacío humano provocó el fracaso del Movimiento. En Galicia, el partido acabó siendo un factor subordinado a todo lo que tenía por encima de él: el gobernador civil.

Aquellas «banderías y capillitas» que se citan en las líneas superiores deben definirse dentro del marco de las distintas almas que se integraban en la Falange unificada. La unión de las distintas fuerzas - falangistas y tradicionalistas-, en el interior del Movimiento fue, como se demuestra, complicada. La diferente cultura política de los dos polos obligó a una difícil configuración del resultado final de su unión. Entrando ya en el debate sobre el papel jugado por el Movimiento en la dictadura franquista, se deben tener en cuenta las diferentes maneras de entender aquél por la historiografía. Por un lado, podemos interpretar que el partido único se convirtió en un instrumento de los militares especialmente durante la guerra civil y los primeros años de la dictadura-, para extender los principios que sustentaban el golpe de Estado (Payne, 2001). Otras interpretaciones consideran que Franco construyó el partido unificado para consolidar su poder y ejercer un control más activo sobre todos los niveles de acción política (Chueca, 1983). Mientras que la perspectiva opuesta a la primera considera que el sujeto FET de las JONS supuso la consecución del deseo de la Falange de alcanzar sus objetivos políticos; esencialmente, la 
revolución nacionalsindicalista, que con el paso del tiempo se convirtió en la revolución perpetuamente pendiente (Preston, 1986).

Resulta evidente que en el seno de FET de las JONS existieron diferentes tendencias que manifestaron objetivos diferenciados entre ellas. Con los cambios que se produjeron en la dictadura a partir de los años 50 del siglo XX, forzados por el devenir histórico internacional, comenzó a hablarse de un cierto «pluralismo limitado». Esto fue una maniobra cosmética de la dictadura para desvincularse de las que habían sido sus coetáneas -Alemania e Italia. A nivel operativo nada importaba la significación política previa de aquellos que integraron FET de las JONS. Lo que importaba era que el proyecto en el que estaban embarcados era uno solo: una «comunidad de objetivos» para el regreso al statu quo anterior a la Segunda República (Cenarro Lagunas, 1997: 78). Esa amalgama, esa conjunción de intereses, fue utilizada por Franco para ir haciéndose con el control del partido a través de colaboradores cercanos que eran miembros de FET de las JONS. Ese proceso es la denominada «domesticación» de la Falange: personajes como Girón, Serrano Suñer o Miguel Primo de Rivera colaboraron en él; y destituciones como la del delegado nacional de Sindicatos, Gerardo Salvador Merino, lo aceleraron. Francisco Franco fue vaciando la Falange del contenido programático y de acción joseantoniano para convertirla en una muleta de la dictadura (Gil Pecharromán, 2008: 53-62).

Las llamadas que hacían los jefes provinciales del Movimiento a la reunión de toda la sociedad alrededor de FET de las JONS tenían como objetivo la construcción de un elemento político-administrativo que pudiese influir en la vida de los gallegos. La necesidad de influir era imperiosa, pues sobre ella se sustentaba toda la construcción administrativa de la dictadura. La construcción no se elaboró buscando el «consenso» de la sociedad en el proyecto, sino la «aceptación». La dictadura no se había impuesto entre la sociedad para mantener los principios consensuales de la tradición política inmediatamente anterior. No tenía por qué hacerlo ya que contaba con el poder de la coerción y presión social. La aceptación política y social del Movimiento - y de toda su estructura administrativa-, se debe interpretar como el proceso de construcción de un «acuerdo» que negó la existencia de un entendimiento total, en lo ideológico, cultural o en lo social, previo entre las partes. Para construir el Movimiento no era necesaria la «afinidad ideológica»; sino una estructura fundamentada en la «obediencia habitual, los costes de oportunidad, los incentivos y la presión» (Cabana Iglesia, 2009: 42).

En el caso de este estudio se infiere claramente que la construcción del partido en Galicia respondió a la posición intermedia explicada por Ricardo Chueca. FET de las JONS como partido único fue una creación del dictador para evitar la posible contestación que se pudiese suscitar en su contra, y para elaborar un altavoz de la doctrina política que le facilitase la ordenación de la masa social. De ahí, que en muchas ocasiones debamos hablar de indefinición en el proceso de construcción de la dictadura franquista. En las provincias gallegas la multiplicidad de orígenes políticos (partidos) —y también en determinados grupos de culturas políticas distintas-, manifiesta esa indefinición. Al partido único le costó penetrar en las distintas capas de la sociedad gallega más que ex- 
tender — limitadamente-, su influencia en los niveles políticos y administrativos (Presas Sobrado, 2019: 125). La indefinición originó las luchas y divisiones internas descritas más arriba. El Movimiento, sin capacidad para entrar en la acción política, carecía de línea clara de ataque. El partido no era lo suficientemente fuerte como para organizar y totalizar los instrumentos de intervención políticos y administrativos. El acceso al poder de aquellos que militaban en su interior se producía no por la pertenencia al Movimiento, sino por una trayectoria política previa, por un caudal de experiencia dentro de una escala ascendente delimitada por la participación política anterior al golpe de estado de julio de 1936. En primer lugar se situarían los falangistas y los tradicionalistas; por debajo, los monárquicos y los definidos como «católicos»y, finalmente, la derecha de tradición no españolista: catalanes, gallegos y vascos (Canales Serrano, 2006: 237-238).

\section{CONCLUSIONES}

Los estudios que se han realizado en Galicia vienen a confirmar esa tendencia general que se observa en el resto de España. La FET de las JONS gallega se nutrió del caudal de los antiguos elementos de la Unión Patriótica, del Partido Republicano Radical, de las marcas locales de la CEDA e, incluso, de algunos elementos de la ORGA (Souto Blanco, 1999, 140). Los hombres del republicanismo galeguista no pueden dejar de citarse en ciudades como Ourense: algunos jóvenes de las Mocidades Galeguistas — la facción juvenil del Partido Galeguista—, se encuadraron antes de la guerra, transitando algunos previamente por las Juventudes de Acción Popular (Prada Rodríguez, 2005: 179-181). En investigaciones recientes se ha podido confirmar que ese recurso a personajes políticos del pasado para rellenar los cuadros de FET de las JONS se consolida en proporciones que superan en más de la mitad el número de casos estudiados (Presas Sobrado, 2019: 468). A pesar de que en Galicia no se desarrolló una alternativa política galeguista de corte reaccionario, el traspaso de elementos del galeguismo activo al falangismo es claro en algunos casos, tales como Álvaro Cunqueiro, Vicente Risco o Eugenio Montes (Presas Sobrado, 2016). Debido a la necesidad de implantarse en un territorio dominado por las redes clientelares —más o menos destacado su papel por la historiografía —, los antiguos upetistas, la burguesía conservadora, los conservadores republicanos y la suma de falangistas, tradicionalistas y católicos, darían como resultado el topónimo por excelencia de los primeros años de la dictadura: la gente de orden (Prada Rodríguez y Grandío Seoane, 2014: 32-33). En línea con lo que sucedía en el resto del territorio, la Falange gallega debió acudir a esos elementos ante la ausencia de cualquier tipo de estructura administrativa y de apoyo social que le permitiese influir decididamente en el ámbito político; tanto anterior como posterior a la guerra civil.

Es por eso por lo que el partido se podía permitir que aquellos que tenían el carné no participasen activamente en el funcionamiento del partido. El partido era una unión sólida de intereses personales no una comunidad de expresión de una cultura política nacionalsindicalista desarrollada plenamente. Una unión que se consolidaba en un con- 
senso, este sí exclusivo y no dudoso: la guerra civil era su punto de unión, y la experiencia en ella era lo que los mantenía unidos contra el objetivo único de evitar una revolución bolchevique en España y la desaparición del statu quo tradicional de clase. «La idea era que en muchos años no se levantara nadie» (Casanova, 2004: 13). Eso explica que cuando los jefes provinciales informaban sobre la inexistencia de estructuras administrativas del partido, a la vez solicitasen un mayor grado de indicaciones a sus jerarquías para terminar de dotar de un rumbo claro al Movimiento; para mantener unida a la masa dentro del redil del Movimiento. Como se ha visto en los resultados anteriores, las disputas que se producían en el seno del partido hicieron de FET de las JONS el campo de una constante lucha de intereses entre las facciones del partido. La esencia de las disputas era la búsqueda necesaria del crecimiento personal en el ámbito local, combinando el crecimiento con el mantenimiento de las cuotas de poder conseguidas con anterioridad (García Ramos, 2003: 140-145 o Sanz Alberola, 1999: 92-94). Las instituciones, por consiguiente, fueron los elementos que enfrentaron a los diferentes sectores del Movimiento en Galicia. Los tira y afloja entre los gobernadores civiles y los jefes provinciales del Movimiento no son más que una muestra clara de esa lucha; que en otras zonas de España se dio también entre aquellas instituciones que controlaban sectores productivos esenciales y aquellas que fijaban las condiciones para la producción de aquéllos (Alcaraz Abellán, 1999: 286).

Los trabajos y análisis sobre la dictadura franquista en el nivel local y el papel de FET de las JONS suelen iniciarse con la reflexión del protagonismo de ésta en la Segunda República, cuando aún era FE de las JONS. Esta reflexión parte de la máxima de que el partido durante la República era minoritario, sin base social potente y propia que lo sustentase. De esa manera, suele reducirse el fascismo/falangismo previo a la guerra civil a una élite de jóvenes - y no tan jóvenes monárquicos, o simplemente reaccionarios provenientes de sectores derechistas radicalizados en el Bloque Nacional de José Calvo Sotelo-, que no estaban cómodos dentro del juego democrático y que, como no tenían manera de actuar dentro del sistema de partidos, decidieron pasar a la acción directa violenta. Pero esa lectura falla en un punto: un partido no es más o menos poderoso por razón de su presencia en las instituciones de representación. El poder de un partido estaría en su capacidad de movilización social; y ahí fue donde habría residido el poder de la primigenia FE de las JONS, y que se habría transmitido a los momentos iniciales de la guerra civil (Gallego, 2016).

Sirviéndose de ese elemento de movilización poderoso, la dictadura franquista habría actuado como una escoba que eliminó cualquier referencia a la política anterior a ella; especialmente en lo vinculado al sexenio entre abril de 1931 y julio de 1936. Es más, esa pretendida inexistencia del partido con anterioridad a la guerra civil no fue impedimento para que en determinadas zonas de la geografía española jornaleros y campesinos se afiliasen en masa en el momento más delicado de la organización (Lazo Díaz, 1998: 23-25). En la franja meridional de la península — en la provincia de Sevilla, por ejemplo-, un partido casi «inexistente en la zona a comienzos de 1936» pasó a experimentar un elevado crecimiento en cuanto a afiliados y seguidores en el intersticio de febrero-julio 
de 1926 (Parejo Fernández, 2004: 45-46 y Parejo Fernández, 2017). El partido único habría servido para eliminar las pretendidas disfunciones sociales y culturales fruto de la experiencia republicana. La dictadura se fundaba sobre la necesidad de volver al orden social y político tradicional: la clase propietaria - terratenientes, banqueros, industriales_-, debía ocupar su puesto dominante (De Riquer, 1989, 16). La larga duración de la dictadura se explicaría por su capacidad para empaparse de los modos fascistas en su inicio y desprenderse de ellos cuando fue necesario para encontrar su papel en el mundo (la fascistización), y por su capacidad para inculcar entre la sociedad la idea de un regreso al orden que la República había puesto en peligro (Saz, 2004; Molinero, 2007: 290).

El intento final de FET de las JONS por hacerse un hueco en el proceso de construcción institucional y político de la dictadura franquista fue la unificación de los cargos de gobernador civil y jefe provincial del Movimiento. Tanto la historiografía analizada en el apartado anterior como los resultados de la investigación deben llevarnos a cuestionar el supuesto papel protagonista que habría adquirido el Movimiento con esa unificación institucional. El papel subordinado del partido al aparato institucional de la dictadura queda demostrado tanto en la lectura dada por la ciencia política de la academia en la dictadura, como por los restos documentales analizados. FET de las JONS se convirtió en el factor político subordinado al administrativo en manos del hacedor supremo en las provincias (García de Enterría, 1961: 99). La conclusión sobre la unificación de los dos máximos cargos provinciales es que los gobernadores civiles desactivaron la capacidad de acción de FET de las JONS convirtiéndola en un mero brazo ejecutor y altavoz de políticas y acciones públicas. Aun así, hay quien entiende esa unificación como un triunfo del partido al haber sido reclamada por la propia Falange unificada (Sanz Hoya, 2014: 59-60); y, de manera más evidente, como el punto más cercano de la dictadura franquista al fascismo italiano (Calvo Vicente, 1993: 20). El supuesto éxito de partido no sería más que una victoria sobre el papel. La posibilidad de colocar en los puestos de gobernador civil a falangistas - como observa Sanz Hoya en su trabajo_- en el caso de Galicia se localizó en una de las provincias, siendo el resto militares nada próximos a los principios nacionalsindicalistas.

FET de las JONS cargó desde sus inicios una serie de lastres que dificultaron su trabajo en la construcción del entramado institucional de la dictadura y en los años posteriores. El Movimiento, a la luz de la historiografía, nació de una suma de intereses de diferentes facciones políticas, que tenían como único objetivo cumplir sus necesidades particulares: copar las mayores cotas de poder. FET de las JONS, como partido único se demostró incapaz de conservar el carácter movilizador de los primeros años de la dictadura, perdiendo peso específico en favor de las estructuras del Estado como la representada por los gobernadores civiles. Los estudios demuestran que el proceso de unificación es el máximo exponente de la multiplicidad de orígenes e identidades políticas que, como una ola, se subsumieron en FET de las JONS (Rodríguez Barreira, 2013: 205-214); y también algunos creen ver en ella el pico máximo del dominio político de la organización (Marín i Corbera, 2000: 202). Aún teniendo en cuenta esta última afirmación, su papel se ha demostrado siempre testimonial; accesorio; decorativo. Sin embargo, también, notorio. 


\section{BIBLIOGRAFÍA}

Alcaraz Abellán, J. (1999): Instituciones y sociedad en Gran Canaria (1936-1960), Las Palmas de Gran Canaria, Ediciones del Cabildo de Gran Canaria.

Aróstegui, J. (1992): «Historiografía sobre la España de Franco: promesas y debilidades», Historia contemporánea, 7, pp. 77-100. En línea: <https://www.ehu.eus/ojs/index. php/HC/article/view/19410/17448> [Consultado el 13 de abril de 2020].

Cabana Iglesia, A. (2009): Xente de orde: o consentimento cara o franquismo en Galicia, Santa Comba, trescetres.

Calzado Adaria, A. y Torres Fabra, R.C. (1993): «La formación de un poder omnímodo: la Falange en la Ribera Baixa (1939-1945)», en Tusell, J. et al. (coords.): El régimen de Franco, Congreso Internacional, v. 1, Madrid, UNED, pp. 29-40.

Calvo Vicente, C. (1995): Poder y consenso en Guipúzcoa durante el franquismo (19361951), Salamanca, Universidad de Salamanca, [Tesis doctoral].

Canales Serrano, A. (2006): Las otras derechas: derechas y poder local en el País Vasco y Cataluña en el siglo XX, Madrid, Marcial Pons.

Cenarro Lagunas, Á. (1997): Cruzados y camisas azules: los orígenes del franquismo en Aragón (1936-1945), Zaragoza, Prensas Universitarias de Zaragoza.

Casanova, J. (2004): «Unida dictadura de cuarenta años», en Casanova, J., Mir, C. et al.: Morir, matar, sobrevivir. La violencia en la dictadura de Franco, Barcelona, Crítica: pp. 3-50.

Chueca, R. (1983): El fascismo en los comienzos del régimen de Franco: un estudio sobre FET-JONS, Madrid, Centro de Investigaciones Sociológicas.

Clara, J. (1991): Girona sota el franquisme (1939-1976), Girona, Ajuntament de GironaDiputació de Girona.

De Riquer, B. (1980): «El 'Nuevo Estado' i l'Ajuntament de Barcelona. La classe política del primer franquisme», L'Avenç, mayo, 126, pp. 16-22.

Gallego, F. (2016): «Nacionalsindicalismo y contrarrevolución (1931-1936). La relevancia del fascismo en la Segunda República española», en Morente, F., Pomés, J. y Pigsech, J. (eds.): La rabia y la idea. Política e identidad en la España republicana (1931-1936), Zaragoza, Prensas Universitarias de Zaragoza, pp. 173-202.

García de Enterría, E. (1961): La administración española. Estudios de ciencia administrativa, Madrid, Instituto de Estudios Políticos.

García Ramos, D. (2003): Instituciones y vida política durante la guerra civil y el franquismo en Palencia (1936-1975), UNED, [Tesis doctoral].

Gil Pecharromán, J. (2008): Con permiso de la autoridad. La España de Franco (19391975), Madrid, Temas de Hoy.

Ginés i Sànchez, A. (2010): La instauració del franquisme al País Valencià, València, Publicacions de la Universitat de València.

Giráldez Lomba, A. (1999): «La guerra ha terminado...» Hace sesenta años en Vigo, Vigo, Instituto de Estudios Vigueses. 
Gomez Roda, J.A. (1998): Política i poder local. Catarroja: un municipi valencià durant el primer franquisme, Catarroja, Afers.

González Madrid, D.A. (2004): La Falange manchega (1939-1945). Política y sociedad en Ciudad Real durante la etapa «azul» del primer franquismo, Ciudad Real, Biblioteca de autores Manchegos-Diputación de Ciudad Real.

Grandío Seoane, E. (1993): «El primer personal político del franquismo en la provincia de La Coruña. Cambio y continuidad de las élites políticas municipales durante la guerra civil en la retaguardia», en Tusell, J. et al. (coords.): El régimen de Franco, Congreso Internacional, v. 1, Madrid, UNED, pp. 69-87.

Herrero Tejedor, F. (1962): La figura del Gobernador Civil y jefe provincial del Movimiento, Madrid, Foro de Ideas-Nuevo Horizonte.

Lazo Díaz, A. (1998): Retrato del fascismo rural en Sevilla, Sevilla, Universidad de Sevilla.

Marín i Corbera, M. (2000): Els ajuntaments franquistes a Catalunya, Lleida, Pagès editors.

Mas Quetglas, J. (2003): Els mallorquins de Franco. La Falange i el Moviment Nacional, Palma de Mallorca, Documenta Balear.

Millares Cantero, A. (2014): «Los monárquicos saludan a la romana. Notas sobre el primer fascismo grancanario», en León Álvarez, A. (coord.): El Franquismo en Canarias, Santa Cruz de Tenerife, LeCanarien ediciones, pp. 108-145.

Molinero, C. (2007): «Present i futur de la historiografía sobre el règim franquista», en Font Agulló, J. (dir.): Història i Memòria: el franquisme i els seus efectes als Països Catalans, València, Publicacions de la Universitat de València.

Parejo Fernández, J.A. (2004): La Falange en la Sierra Norte de Sevilla (1934-1956), Sevilla, Universidad de Sevilla, Ateneo de Sevilla.

Parejo Fernández, J.A. (2017): «Cuando fueron jóvenes... y fascistas», en Del Rey, F. y Álvarez Tardío, M. (dirs.): Políticas del odio. Violencia y crisis en las democracias de entreguerras, Madrid, Tecnos, pp. 167-231.

Payne. Stanley G. (2001): El fascismo, Madrid, Alianza.

Ponce Alberca, J. (2016): «Los gobernadores civiles en el primer franquismo», Hispania, v. 76, 252, pp. 245-271.

Prada Rodríguez, J. (2005): A dereita política ourensá: monárquicos, católicos e fascistas (1934-1937), Vigo, Servizo de Publicacions da Universidade de Vigo.

Prada Rodríguez, J. y Grandío Seoane, E. (2014): «La gestión del poder local: viejas y nuevas élites» en Prada Rodríguez, J. (dir.): No solo represión. La construcción del franquismo en Galicia, Madrid, Biblioteca Nueva, pp. 29-59.

Presas Sobrado, A. (2016): «Eugenio Montes: o discurso dun pensador da dereita reaccionaria española», Minius: revista do departamento de Historia, Arte e Xeografía, 24, pp. 271-291.

Presas Sobrado, A. (2019): Elites políticas e poder local na Galicia urbana (1939-1951), Ourense, Universidade de Vigo, [Tesis doctoral]. 
Preston, P. (1986): Las derechas españolas en el siglo XX: autoritarismo, fascismo y golpismo, Madrid, Sistema.

Rivero Noval, M.C. (2001): Política y sociedad en La Rioja durante el primer franquismo (1936-1945), Logroño, Instituto de Estudios Riojanos.

Rodríguez Barreira, Ó. (2013): Miserias del poder: los poderes locales y el nuevo estado franquista, València, Publicacions de la Universitat de València.

Sanz Alberola, D. (1999): La implantación del franquismo en Alicante, Alicante, Universidad de Alicante.

Sanz Hoya, J. (2014): «FET-JONS en las instituciones provinciales y locales de la dictadura franquista», en León Álvarez, A. (coord.): El Franquismo en Canarias, Santa Cruz de Tenerife, LeCanarien ediciones, pp. 52-68.

Saz, I. (2004): Fascismo y franquismo, València, Publicacions de la Universitat de València.

Souto Blanco, M.J. (1999): La represión franquista en la provincia de Lugo (1936-1940), Sada, Ediciós do Castro.

Thomàs, J.M. (1992): Falange, Guerra Civil, Franquisme. FET y de las JONS de Barcelona en els primers anys del règimen franquista, Barcelona, Publicacions de l'Abadia de Montserrat.

Tusell, J. (1993): «La dictadura de Franco a los cien años de su muerte», Ayer, 10, pp. 13-28. En línea: <http://revistaayer.com/sites/default/files/articulos/10-1-ayer10_ LaHistoriaene192_Fusi.pdf> [Consultado el 13 de abril de 2020]. 